\title{
Gastrointestinal and segmental colonic transit times in patients with acute and chronic spinal cord lesions
}

\author{
$\mathrm{K} \mathrm{Krogh}^{*, 1} \mathrm{C}_{\mathrm{Mosdal}^{2}}$ and S Laurberg ${ }^{1}$ \\ ${ }^{1}$ Surgical Research Unit, Department of Surgery L, Section AAS, University Hospital of Aarhus, Denmark; \\ ${ }^{2}$ Department of Neurosurgery GS, University Hospital of Aarhus, Denmark
}

Study design: Longitudinal study among patients with acute and chronic spinal cord injuries (SCI).

Objectives: To compare total gastrointestinal transit times (GITT) and segmental colorectal transit times (CTT) in SCI patients with acute and chronic lesions to those of healthy volunteers. Furthermore, to examine the impact of time elapsed since injury on GITT and CTT, and finally to compare the pattern of colorectal dysfunction in patients with supraconal versus conal/cauda equina lesions.

Setting: Surgical Research Unit and Department of Neurosurgery, University Hospital of Aarhus, Denmark.

Methods: Patients took 10 radioopaque markers on six consecutive days and an abdominal X-ray was taken on day 7. GITT and CTTs were computed from the number of markers in the entire colorectum and in each colorectal segment respectively. We studied 26 patients with acute spinal cord lesions (15 supraconal and 11 conal/cauda equina lesions; time since injury $=11-24$ days) and 18 patients were available for follow-up $6-14$ months later. Results were compared to 24 healthy volunteers.

Results: In patients with acute supraconal or conal/cauda equina lesions GITT and CTTs of the ascending, transverse, and descending colon were significantly prolonged, but rectosigmoid transit time was only significantly prolonged in patients with conal/cauda equina lesions. In patients with chronic supraconal lesions GITT and CTTs of the transverse colon and the descending colon were significantly prolonged. In patients with chronic conal/cauda equina lesions GITT and CTT of the transverse, the descending colon and the rectosigmoid were significantly prolonged. Thus, supraconal SCI resulted in generalized colonic dysfunction whereas chronic conal/cauda equina lesions resulted in severe rectosigmoid dysfunction.

Conclusion: SCI results in severely prolonged colonic transit times both in the acute and chronic phase. However, the type of colorectal dysfunction depends on the level of SCI.

Spinal Cord (2000) 38, 615-621

Keywords: spinal cord injury; cauda equina; colon; rectum; constipation; motility

\section{Introduction}

Colorectal and anal sphincter dysfunction resulting in constipation, obstructed defecation or fecal incontinence are common complications to spinal cord injury (SCI) ${ }^{1-5}$ Only few SCI patients feel normal desire to defecate and most use laxatives, enemas or digital stimulation of the rectum and anal canal to initiate defecation. Furthermore, colorectal problems often restrict patients social activities and influence their quality of life. ${ }^{1,2}$ In spite of the large number of SCI patients, their colorectal function is very incompletely understood.

Most studies of segmental colonic transit time in SCI patients have either been restricted to patients with complete lesions ${ }^{6,7}$ or they have contained a very

*Correspondence: $\mathrm{K}$ Krogh, Surgical Research Unit, Aarhus Amtssygehus, Tage Hansensgade 2, 8000 Aarhus C, Denmark small number of patients. ${ }^{8}$ As about $40 \%$ of patients have incomplete lesions, ${ }^{9}$ colonic transit time after incomplete SCI is clinically very important too. Furthermore, colonic transit time in patients with lesions of the conus medullaris and the cauda equina needs further study. All previous studies have been in the chronic phase of SCI. ${ }^{6-8,10}$ In the acute phase colorectal function may be more severely affected due to spinal shock, analgesics and immobilization.

The aim of this study was to describe total gastrointestinal and segmental colonic transit times in patients with complete or incomplete SCI both in the acute and the chronic phase. Furthermore, the aim was to test the hypothesis that constipation in patients with conal or cauda equina lesions is predominantly rectosigmoid whereas it is more generalized in patients with supraconal lesions. 


\section{Methods}

\section{Patients}

All acute spinal cord injured patients from the Western part of Denmark (population: 2.5 million) are admitted to the Department of Neurosurgery at University Hospital of Aarhus. From February 1st 1996 to December 31st 1997 all patients with acute SCI were asked to participate in the study if they fulfilled the following criteria:

(1) had sustained a SCI within the last 21 days.

(2) did not have lesions of other organs preventing them from the intake of transit markers or from transport.

(3) were in a physical and psychological state which did not make the request to participate in the study unethical.

(4) were adults less than 65 years of age.

(5) had a permanent address in the Western part of Denmark.

(6) had neurological deficit that did not resolve within 2 weeks after injury.

A total of 32 patients fulfilled the inclusion criteria. Among these, three $(9 \%)$ did not wish to participate in the study and another three $(9 \%)$ were excluded after inclusion due to severe ileus, pulmonary embolism and a severe urinary tract infection. Thus, colonic transit time was measured in 26 patients with acute SCI. Lesions were caused by trauma ( 24 patients), acute disc prolapse (one patient) and spinal thrombosis (one patient).

Forty-one patients ( 31 with supraconal lesions) were not asked to participate in the study. The reasons for this were: patients were unconscious (four patients), severe respiratory complications (nine patients), unstable fractures of dens axis (two patients), lesions caused by suicidal attempts (seven patients), age more than 65 years (five patients) or less than 17 years (five patients), died before inclusion (three patients), severe trauma to other organs (two patients), severe urinary tract infections (two patients) or permanent address outside the Western part of Denmark (two patients).

The International Standards for Neurological and Functional Classification of Spinal Cord Injury were used for the description of the level and severity of lesions. ${ }^{11}$ According to these, lesions were supraconal in 15 patients (six with cervical lesions, six with thoracic lesions above T9, two with lower thoracic lesions and one with a lumbar lesion). The remaining 11 patients had lesions of the conus medullaris (six patients) or of the cauda equina (five patients).
Before SCI two patients defecated less than twice a week, all other patients had normal bowel function without fecal incontinence and with spontaneous defecation every or every second day. One patient with a lesion at T4 had had a resection of a part of the small bowel several years before. Another with a lesion at $\mathrm{C} 5$ had been operated on for a cerebral aneurism 5 years before injury.

Further data about patients are shown in Table 1.

\section{Gastrointestinal and segmental colonic transit times}

Gastrointestinal and segmental colonic transit times were determined by the method described by Abrahamsson et al. ${ }^{12}$ Patients ingested 10 ringshaped radioopaque markers with a diameter of $5 \mathrm{~mm}$ (Medifact, Gotenburg, Sweden) at noon on six consecutive days. On day 7 a single abdominal X-ray was taken. From bony landmarks and the gaseous outline of the bowel, the colorectum was divided into the ascending colon (including the right colic flexure), the transverse colon, the descending colon (including the left colic flexure), and the rectosigmoid. The number of markers was counted in each segment and in the entire colorectum. Thereby the whole gut or gastrointestinal transit time $\left(\mathrm{GITT}_{\mathrm{d}}\right)$ in days could be computed:

$$
\mathrm{GITT}_{\mathrm{d}}=(\mathrm{M}+(\mathrm{f} \times \mathrm{D})) / \mathrm{D}
$$

where $\mathrm{D}$ is the number of markers taken each day, $\mathrm{M}$ is the total number of markers counted from the X-ray, and $\mathrm{f}$ is the fraction of the daily number of markers chosen for estimation of transit. Gastrointestinal transit time is normally defined as the mean half emptying of the gut. This means that the transit time increases by 1 day when half the markers taken daily are passed. Therefore, $\mathrm{f}$ is $0.5 .^{12}$ If for example 15 markers were left on the abdominal X-ray, the GITT $_{\mathrm{d}}$ would be: (15 markers $+\left(0.5\right.$ day $^{-1} \times 10$ markers $/$ day $\left.)\right) / 10$ markers $/$ day $=$ 2.0 days.

Segmental colonic transit times in days were computed for each colonic segment as $\mathrm{N} / \mathrm{D}$, where $\mathrm{N}$ is the number of markers in the segment and $\mathrm{D}$ is the daily intake of markers $(\mathrm{D}=10)$. If for example, nine markers were left in the rectosigmoid the transit time of that segment would be: nine markers/10 markers/ day $=0.9$ days

In order to determine transit times before patients were transferred to another centre for rehabilitation, patients started the intake of markers for determina-

Table 1 Patients and healthy controls included in the study

\begin{tabular}{|c|c|c|c|}
\hline & Supraconal lesions & $\begin{array}{l}\text { Conus medullaris or } \\
\text { cauda equina lesions }\end{array}$ & Healthy controls \\
\hline Number of persons: & 15 (11 men, 73\%) & 11 (7 men, 64\%) & 24 (16 men, 67\%) \\
\hline Age (years): & $17-69($ median $=34)$ & $22-63($ median $=38)$ & $23-60($ median $=32)$ \\
\hline Complete lesions: & $6(40 \%)$ & $2(18 \%)$ & - \\
\hline Days since injury & $11-24($ median $=18)$ & $11-24($ median $=15)$ & - \\
\hline
\end{tabular}


tion of transit time as soon as possible. Thus, some variability had to be accepted and the intake of markers for transit time was started 4 to 17 days $($ mean $=9)$ after the lesion, and consequently, the transit times were determined 11 to 24 days $($ mean $=16)$ postinjury. Furthermore, as many patients lived in different parts of the country, it was impossible to see all at a fixed time after injury. However, in all patients available for follow-up, gastrointestinal and colonic transit times were repeated six to 14 months after injury, when patients were assumed to be in the chronic phase. Patients were compared with 24 healthy volunteers mainly recruited among hospital staff and students (Table 1). The same control group was used in the acute phase and at follow-up.

Patients and controls kept a dietary record for 3 days ( 2 working days and a day in the weekend) while taking transit markers. The diet was analyzed by a dietician by means of the computer programme Dankost (Danish Catering Center, Herlev, Denmark). The average total daily energy intake and the average daily intake of proteins, fat, carbohydrates, alcohol and fibers were computed. Furthermore, the energy intake covered by proteins, fat, carbohydrates and alcohol was computed as percentage of the daily energy intake. The use of oral laxatives, suppositories and digital evacuation of the rectum was also noted. Furthermore, patients colorectal function was described in a questionnaire. This was done in the acute phase and at follow-up.

The study was approved by the Ethical Committee for the County of Aarhus, Denmark (Journalnr. 1995/ 3372).

\section{Statistical analysis}

For each group of patients and healthy controls, normal probability plots were made for total GITT $_{\mathrm{d}}$ and all segmental colonic transit times. Results are shown as mean gastrointestinal and segmental transit times in days and, for normally distributed data, standard deviation is shown in addition. The total number of markers in the colorectum and the number of markers in each colonic segment were compared between patient groups and between patients and controls using the Mann-Whitney test with correction for ties. Results are shown as level of significance. $P<0.05$ was considered statistically significant.

To test the hypothesis that conal or cauda equina lesions mainly cause delayed transit of the rectosigmoid, whereas supraconal lesions cause more generalized colorectal dysfunction, the transit time of the rectosigmoid (RTT) was divided by the transit time of the ascending colon (ACTT). This ratio (RTT/ACTT) was computed in all subjects in the control group and in patients with chronic lesions, if at least two markers had passed through the entire colorectum. In some subjects there were no markers in the ascending colon and thus the RTT/ACTT would be infinitely large. To avoid this the maximal value for RTT/ACTT was arbitrary set to six, which is 1 day larger than the maximal observed RTT/ACTT. As the two groups were compared using a non parametric test (the MannWhitney test with correction for ties) the actual value of RTT/ACTT in subjects with ACTT $=0$ was not important as long as it was chosen to be more than observed in the remaining subjects.

In patients available for follow-up, total gastrointestinal transit times and segmental colonic transit times were compared between the acute and the chronic phase by the Mann-Whitney test with correction for ties.

The total energy intake and the intake of proteins, fat, carbohydrates, fibers and alcohol was compared between patient groups and controls by the MannWhitney test with correction for ties.

\section{Results}

\section{Bowel symptoms in patients with acute and chronic spinal cord lesions}

Medication affecting colorectal motility At inclusion one patient with an acute supraconal lesion and two with acute cauda equina lesion used morphine in doses from 10 to $20 \mathrm{mg}$ daily because of pain in the back. One patient with an acute supraconal lesion had supplementary intake of iron (Ferroduretter, $200 \mathrm{mg}$ daily) because of anemia. The use of oral laxatives (Laxoberal, 10-20 drops/day), suppositories (Microlax, $5 \mathrm{ml})$, or phosphate enema $(7.5 \mathrm{ml})$ in the acute and chronic phase is shown in Table 2.

Bowel function At the time the abdominal X-rays were taken, four patients $(27 \%)$ with acute supraconal lesions had not defecated since injury. One patient defecated every day, two every second day, and eight less than once every second day. Three patients $(27 \%)$ with acute conal or cauda equina lesions had not yet defecated, while eight defecated less than every second day.

In $24(92 \%)$ patients with acute lesions, defecation was initiated by suppositories, klysma, or digital stimulation of the rectum. Thus, only two patients had normal controlled defecation. No patients were able to empty the bladder normally.

At follow-up, seven of $10(70 \%)$ patients with supraconal and four of eight $(50 \%)$ patients with conal or cauda equina lesions had to initiate defecation by suppositories, klysma or digital stimulation or emptying of the rectum. Three of nine $(33 \%)$ patients with supraconal and three of eight $(43 \%)$ with conal or cauda equina lesions needed more than $30 \mathrm{~min}$ for each defecation. Furthermore, four of $10(40 \%)$ and three of eight $(43 \%)$ respectively suffered from episodes of fecal incontinence. At follow-up, bladder function was abnormal in seven of $10(70 \%)$ patients with supraconal lesions and in four of seven $(57 \%)$ with conal or cauda equina lesions. 
Further information about symptoms are shown in Table 2

Total gastrointestinal and colonic transit times in patients with acute SCI

Total gastrointestinal transit time was significantly prolonged in patients with acute supraconal lesions and in patients with acute lesions of the conus medullaris or cauda equina (Table 3). In patients with acute supraconal SCI, transit times of the ascending colon, the transverse colon, and the descending colon, but not the rectosigmoid were significantly prolonged (Table 3). In patients with acute lesions of the conus medullaris or cauda equina all segmental colonic transit times were significantly prolonged (Table 3 ).

Among healthy volunteers the mean total gastrointestinal transit time was 1.76 days and the corresponding $95 \%$ confidence interval was 0.19 to 3.33 days. Only five $(33 \%)$ patients with acute supraconal lesions and two $(18 \%)$ patients with acute conal or cauda equina lesions had total gastrointestinal transit times within this range. Thus, $19(73 \%)$ patients with acute SCI (supraconal or conal/cauda equina) had prolonged total gastrointestinal transit times.

Comparing patients with acute supraconal lesions to those with acute lesions of the conus medullaris or cauda equina, no significant differences were found. Furthermore, in the acute phase, no statistically significant differences in neither total gastrointestinal transit time nor segmental colonic transit times were found between patients with complete and patients with incomplete SCI. Total gastrointestinal transit time was not correlated to the number of days (range $11-24)$ since injury $\left(r^{2}=0.004\right)$.

\section{Total gastrointestinal and colonic transit times in patients with chronic SCI}

Nineteen patients were available for follow-up. In one of these, the assessment of colonic transit time was invalid because his dog had swallowed half the markers. Thus, total gastrointestinal and segmental colonic transit times were determined in $10(67 \%)$ patients with chronic supraconal lesions and in eight $(73 \%)$ patients with chronic conal or cauda equina lesions. Time since injury was 8-14 months $($ mean $=11.6)$ in patients with supraconal lesions and 6-14 months $($ mean $=11.1)$ in patients with conal or cauda equina lesions. The reason why some patients were not followed up was mainly that they lived far from our center. Others felt that adjusting to their new situation required all their energy and they did not have the strength needed for further visits at hospital.

In patients with chronic supraconal lesions; total gastrointestinal transit time and transit times of the transverse and descending colon were significantly prolonged (Table 3 ). However, restricting the analysis to patients with complete supraconal lesions $(n=5)$; total gastrointestinal transit time $(P<0.001)$ and transit times of the ascending colon $(P<0.05)$, transverse colon $(P<0.001)$, descending colon $(P<0.01)$ and rectosigmoid $(P<0.01)$ were all significantly prolonged. Comparing patients with com-

Table 2 Colorectal function in patients with acute and chronic spinal cord lesions

\begin{tabular}{|c|c|c|c|c|c|c|c|}
\hline & $\begin{array}{l}\text { Defecation } \\
\text { less than } \\
\text { every second } \\
\text { day }\end{array}$ & $\begin{array}{l}\text { Suppositories } \\
\text { of Klysma } \\
\text { every or } \\
\text { every second } \\
\text { day }\end{array}$ & $\begin{array}{c}\text { Daily use of } \\
\text { oral } \\
\text { laxatives }\end{array}$ & $\begin{array}{c}\text { Digital } \\
\text { stimulation } \\
\text { of the rectum }\end{array}$ & $\begin{array}{c}\text { Fecal } \\
\text { incontinence }\end{array}$ & $\begin{array}{l}\text { Need }>30 \\
\text { min per } \\
\text { defecation }\end{array}$ & $\begin{array}{l}\text { Neurogenic } \\
\text { bladder } \\
\text { dysfunction }\end{array}$ \\
\hline $\begin{array}{l}\text { Patients with acute } \\
\text { supraconal lesions } \\
(n=15)\end{array}$ & $9(60 \%)$ & $14(93 \%)$ & $12(80 \%)$ & $1(7 \%)$ & $5(50 \%)^{b}$ & - & $15(100 \%)$ \\
\hline $\begin{array}{l}\text { Patients with acute } \\
\text { conal or cauda } \\
\text { equina lesions } \\
(n=11)\end{array}$ & $4(36 \%)$ & $8(73 \%)$ & $8(73 \%)$ & $1(9 \%)$ & $4(36 \%)$ & - & $11(100 \%)$ \\
\hline $\begin{array}{l}\text { Patients with } \\
\text { chronic supraconal } \\
\text { lesions }(n=10)\end{array}$ & $0^{\mathrm{a}}$ & $5(50 \%)$ & $5(50 \%)$ & $6(60 \%)$ & $4(40 \%)$ & $3(33 \%)^{b}$ & $7(70 \%)$ \\
\hline $\begin{array}{l}\text { Patients with } \\
\text { chronic conal or } \\
\text { cauda equina lesions } \\
(n=9)\end{array}$ & $0^{\mathrm{a}}$ & $2(22 \%)$ & 0 & $4(44 \%)$ & $3(43 \%)^{b}$ & $3(43 \%)^{b}$ & $4(57 \%)^{b}$ \\
\hline
\end{tabular}

${ }^{a}$ In five $(50 \%)$ patients with chronic supraconal lesions and four $(44 \%)$ patients with chronic conal or cauda equina lesions defecation was usually initiated by suppositories or digital stimulation of the rectum; ${ }^{b}$ Due to missing values the percentage of patients with this symptom is not of the total number of patients 
Table 3 Total gastrointestinal and segmental colonic transit times in acute and chronic spinal cord injured

\begin{tabular}{|c|c|c|c|c|c|}
\hline & $\begin{array}{l}\text { Ascending } \\
\text { colonic transit } \\
\text { time (in days) } \\
\text { Mean and }(S D)\end{array}$ & $\begin{array}{l}\text { Transverse } \\
\text { colonic transit } \\
\text { time (in days) } \\
\text { Mean and (SD) }\end{array}$ & $\begin{array}{l}\text { Descending } \\
\text { colonic transit } \\
\text { time (in days) } \\
\text { Mean and (SD) }\end{array}$ & $\begin{array}{l}\text { Rectosigmoid } \\
\text { transit time } \\
\text { (in days) } \\
\text { Mean and (SD) }\end{array}$ & $\begin{array}{l}\text { Total gastrointestinal } \\
\text { transit time (in days) } \\
\text { Mean and (SD) }\end{array}$ \\
\hline Healthy controls & $0.44^{\mathrm{a}}$ & $0.10^{\mathrm{a}}$ & $0.38^{\mathrm{a}}$ & $0.34^{\mathrm{a}}$ & $1.76(0.80)$ \\
\hline Acute supraconal lesions & $\begin{array}{l}1.15(0.65) \\
P<0.01\end{array}$ & $\begin{array}{l}0.50^{\mathrm{a}} \\
P<0.01\end{array}$ & $\begin{array}{l}1.61(0.69) \\
P<0.0001\end{array}$ & $\begin{array}{l}0.84^{\mathrm{a}} \\
P=0.11\end{array}$ & $\begin{array}{l}4.25(1.72) \\
P<0.0001\end{array}$ \\
\hline $\begin{array}{l}\text { Acute conus medullaris } \\
\text { or cauda equina lesions }\end{array}$ & $\begin{array}{l}1.46(0.96) \\
P<0.01\end{array}$ & $\begin{array}{l}0.78(0.43) \\
P<0.0001\end{array}$ & $\begin{array}{l}1.38(0.66) \\
P<0.001\end{array}$ & $\begin{array}{l}0.81(0.50) \\
P<0.01\end{array}$ & $\begin{array}{l}4.91(1.48) \\
P<0.0001\end{array}$ \\
\hline $\begin{array}{l}\text { Chronic supraconal } \\
\text { lesions }\end{array}$ & $\begin{array}{l}0.96^{\mathrm{a}} \\
P=0.06\end{array}$ & $\begin{array}{l}0.52(0.38) \\
P<0.01\end{array}$ & $\begin{array}{l}1.27^{\mathrm{a}} \\
P<0.05\end{array}$ & $\begin{array}{l}0.69^{\mathrm{a}} \\
P=0.15\end{array}$ & $\begin{array}{l}3.93(2.24) \\
P<0.05\end{array}$ \\
\hline $\begin{array}{l}\text { Chronic conus medullaris } \\
\text { or cauda equina lesions }\end{array}$ & $\begin{array}{l}0.55(0.36) \\
P=0.36\end{array}$ & $\begin{array}{l}0.40^{\mathrm{a}} \\
P<0.05\end{array}$ & $\begin{array}{l}1.07(0.73) \\
P<0.05\end{array}$ & $\begin{array}{l}1.14(0.64) \\
P<0.01\end{array}$ & $\begin{array}{l}3.61(1.80) \\
P<0.05\end{array}$ \\
\hline
\end{tabular}

Total gastrointestinal and segmental colonic transit times in days are shown as mean and standard deviation. ${ }^{a}$ means that results were not normal distributed. $P$ values are level of significance when compared to healthy controls using Mann-Whitney test with correction for ties

plete supraconal lesions $(n=5)$ to those with incomplete lesions $(n=5)$; total gastrointestinal transit time $(P<0.05)$, descending colonic $(P<0.05)$ and rectosigmoid $(P<0.05)$ transit times were significantly longer in patients with complete lesions.

In patients with chronic lesions of the conus medullaris or cauda equina total gastrointestinal transit time and transit times of the transverse colon, the descending colon, and the rectosigmoid were significantly prolonged (Table 3 ). No comparison was made between patients with complete and incomplete chronic conal or cauda equina lesions because only one patient had a complete lesion at follow-up.

No correlation was found between total gastrointestinal transit time and months (range 6-14) since injury $\left(r^{2}=0.08\right)$.

\section{Ratio: rectosigmoid transit time/ascending colonic transit time}

The median ratio: rectosigmoid transit time/ascending colonic transit time (RTT/ACTT) as 1.91 in the control group, 0.69 in patients with chronic supraconal lesions and 3.44 in patients with chronic conal or cauda equina lesions. The difference between patients with supraconal and patients with conal or cauda equina lesions was statistically significant $(P<0.05)$.

\section{The effects of sympathetic denervation}

Mean (SD) total gastrointestinal transit time was 2.92 (2.41) days in patients with chronic lesions above the sympathetic outflow for the colorectum (above T9) and 2.84 (1.93) days in patients with chronic lesions located within the spinal segments providing sympathetic outflow for the colorectum (T10 to L2) $(P=0.20)$. Comparing patients with lesions above T10 to those with lesions between $\mathrm{T} 10$ and L2, mean transit times were 0.84 vs 0.83 days $(P=0.79)$ in the ascending colon, 0.60 vs 0.39 days $(P=0.44)$ in transverse colon, 1.17 vs $1.00(P=0.52)$ days in the descending colon and 0.48 vs 0.66 days $(P=0.20)$ in the rectosigmoid.

\section{Acute versus chronic lesions}

In both patient groups, mean total gastrointestinal transit time was longer in the acute than in the chronic phase (Table 3), but differences were not statistically significant $(P=0.43$ for supraconal lesions and $P=0.28$ for conal/cauda equina lesions). In patients with supraconal lesions, no statistically significant differences were found between segmental colonic transit times in the acute and chronic phase (transit times of: the ascending colon $P=0.08$, transverse colon $P=0.50$, descending colon $P=0.25$, and rectosigmoid $P=0.60)$. Also in patients with conal or cauda equina lesions no statistically significant differences were found between acute and chronic segmental colonic transit times (transit times of: ascending colon $P=0.09$, transverse colon $P=0.08$, descending colon $P=0.25$, and rectosigmoid $P=0.10)$.

\section{Energy intake}

In the acute phase, total energy intake $(\mathrm{kJ} / \mathrm{day})$, the intake of fat (g/day) and fibers (g/day) were significantly lower among patients than in the control group (Table 4). In the chronic phase, the total energy intake $(\mathrm{kJ} /$ day) and the intake of fat $(\mathrm{g} /$ day) were significantly lower among patients with supraconal lesions than in the control group (Table 4). This difference was not found for patients with chronic conal or cauda equina lesions. Further information about energy intake is found in Table 4. 
Table 4 Energy intake

\begin{tabular}{|c|c|c|c|c|c|c|c|c|c|}
\hline & $\begin{array}{c}\text { Total } \\
\text { energy } \\
\text { intake } \\
(\mathrm{kJ} / \text { day })\end{array}$ & $\begin{array}{l}\text { Protein } \\
\text { (g/day) }\end{array}$ & $\begin{array}{l}\text { Protein } \\
(\% \text { of } \\
\text { energy } \\
\text { intake) }\end{array}$ & $\begin{array}{c}\text { Fat } \\
\text { (g/day) }\end{array}$ & $\begin{array}{l}\text { Fat } \\
(\% \text { of } \\
\text { energy } \\
\text { intake })\end{array}$ & $\begin{array}{c}\text { Carbonhydrates } \\
\text { (g/day) }\end{array}$ & $\begin{array}{c}\text { Carbonhydrates } \\
\text { (\% of energy } \\
\text { intake })\end{array}$ & $\begin{array}{l}\text { Fibres } \\
\text { (g/day) }\end{array}$ & $\begin{array}{l}\text { Alcohol } \\
(\% \text { of } \\
\text { energy } \\
\text { intake })\end{array}$ \\
\hline Healthy controls & 10094 & 78 & 13 & 91 & 34 & 290 & 49 & 23 & 4 \\
\hline \multirow{2}{*}{$\begin{array}{l}\text { Acute supraconal } \\
\text { lesions }\end{array}$} & 7550 & 63 & 14 & \multirow{2}{*}{$\begin{array}{c}63 \\
P<0.01\end{array}$} & 31 & 233 & 54 & \multirow{2}{*}{$\begin{array}{c}15 \\
P<0.05\end{array}$} & 1 \\
\hline & $P<0.05$ & ns & ns & & ns & ns & ns & & ns \\
\hline \multirow{2}{*}{$\begin{array}{l}\text { Acute conal or cauda } \\
\text { equina lesions }\end{array}$} & 8414 & 68 & 14 & \multirow{2}{*}{$\begin{array}{c}73 \\
P<0.05\end{array}$} & 34 & 259 & 51 & \multirow{2}{*}{$\begin{array}{c}16 \\
P<0.05\end{array}$} & \multirow{2}{*}{$\begin{array}{c}1 \\
P<0.01\end{array}$} \\
\hline & $P<0.05$ & ns & ns & & ns & $\mathrm{ns}$ & ns & & \\
\hline \multirow{2}{*}{$\begin{array}{l}\text { Chronic supraconal } \\
\text { lesions }\end{array}$} & 6556 & 57 & 15 & \multirow{2}{*}{$\begin{array}{c}52 \\
P<0.05\end{array}$} & 33 & \multirow{2}{*}{$\begin{array}{c}208 \\
\text { ns }\end{array}$} & 52 & \multirow{2}{*}{$\begin{array}{l}15 \\
\text { ns }\end{array}$} & \multirow{2}{*}{$\begin{array}{c}1 \\
\text { ns }\end{array}$} \\
\hline & $P<0.05$ & ns & ns & & ns & & ns & & \\
\hline \multirow{2}{*}{$\begin{array}{l}\text { Chronic conal or } \\
\text { cauda equina lesions }\end{array}$} & 9437 & 85 & 15 & 89 & 36 & 241 & \multirow{2}{*}{$\begin{array}{c}43 \\
P<0.05\end{array}$} & 18 & 6 \\
\hline & ns & ns & ns & ns & ns & ns & & ns & ns \\
\hline
\end{tabular}

Mean energy intake in healthy controls and patient groups. Level of significance is when patient groups are compared to the control group

\section{Discussion}

As shown in this study, SCI causes profound changes in colorectal luminal transport. Accordingly, colorectal problems are common among SCI patients ${ }^{1-4}$ and also the incidence of colorectal cancer is increased. ${ }^{13}$

Colorectal transit times in patients with acute SCI have not been studied before. We found that mean total gastrointestinal transit times were more than twice as long in patients with acute supraconal or conal/cauda equina lesions as in the control group. This was in spite of the widespread and necessary use of oral laxatives and suppositories. Some patients had not yet defecated when the X-rays were taken at least 11 days after injury and most others had only had a few defecations. Our findings are in accordance with a computer search for serious gastrointestinal complications among acute SCI patients in which Gore et al ${ }^{14}$ found that reflex ileus was the most common gastrointestinal complication. In the acute phase, transit times were prolonged throughout the colon and not only in the left colon receiving its parasympathetic innervation from the sacral segments of the spinal cord. This could be due to combinations of spinal shock, immobilization, a general reaction to a large trauma, the use of opoid analgesics in some patients, and reduced dietary intake of energy and fibers. Rectosigmoid transit time was significantly prolonged in patients with acute conal or caudal equina lesions but not in patients with acute supraconal lesions. This is probably because supraconal SCI leave the reflex arc between the rectum and the sacral spinal cord intact facilitating reflex emptying of the rectum by suppositories, klysma or digital stimulation. The same findings could also indicate that patients were no longer in the spinal shock phase when studied 11 to 24 days after injury. The duration of the spinal shock phase is very variable and it depends on the level of the lesion and on which organ system is studied. ${ }^{15}$ Its duration within the colorectum is unknown, but Denny-Brown and Robertson ${ }^{16}$ found a hypotonic rectum in a patient 4 days after SCI and Kuhn found that, clinically, reflex defecation occurred after a mean period of 2 months. ${ }^{17}$

The need for sufficient intake of energy in the acute phase of SCI has been recognized for many years, ${ }^{17}$ but the reduced intake found in our study warrants further study.

Previously, five studies of colonic transit times among patients with chronic SCI have been published. In four patients with incomplete lumbosacral lesions, Devroede found prolonged transit time of the entire colon and rectum. ${ }^{8}$ Colorectal transit time was also generally prolonged in two studies among patients with cervical or thoracic lesions. ${ }^{6,18}$ In contrast BeuretBlanquart, studying 19 patients with complete thoracic, lumbar or sacral lesions, found neither mean right colonic nor mean left colonic transit time prolonged. ${ }^{7}$ Mean rectal transit time was prolonged in patients with lesions below T9 (ie within or below the spinal segments providing sympathetic innervation for the colorectum), but not in those with lesions above this level. In patients with cervical or thoracic lesions Nino-Murcia ${ }^{10}$ found that total and left, but not right, colonic transit times were prolonged. Thus, some controversy exists about the extent of colorectal involvement after SCI.

We found that total gastrointestinal transit time was significantly prolonged in patients with chronic supraconal as well as in patients with chronic conal/ cauda equina lesions. However, patients with chronic supraconal SCI had significantly prolonged transit times of the transverse and the descending colon but not the rectosigmoid. Ascending colonic transit time tended to be prolonged, though the difference did not reach statistical significance $(P=0.06)$. In patients with 
chronic conal or cauda equina lesions transit times were significantly prolonged in the transverse colon, the descending colon and in the rectosigmoid, but not in the ascending colon. Thus, supraconal SCI caused left and right colonic dysfunction but less severe rectosigmoid dysfunction, whereas conal or cauda equina lesions also caused very severe rectosigmoid dysfunction. In contrast, patients with conal or cauda equina lesions are usually mobile and have a normal daily intake of energy and dietary fibers restricting colorectal problems to the left colon and rectum receiving innervation from the sacral spinal cord. However, as the reflex arc from rectum to the spinal cord is directly affected, rectal evacuation becomes severely compromised resulting in very prolonged rectosigmoid transit times.

No statistically significant differences were found in total gastrointestinal or segmental colonic transit times between patients with lesions directly affecting the sympathetic outflow for the colorectum and those with lesions above this level. This is in contrast to a previous study ${ }^{7}$ and may confirm that parasympathetic stimuli are more important to colorectal transport than sympathetic stimuli. This is in accordance with the clinical observation that total bilateral sympathectomy does not result in any obvious alterations of bowel habits. ${ }^{19}$ However, in our study the number of patients with supraconal lesions located below T9 was too small to allow any definite conclusions about the effect of sympathetic innervation on colorectal transport.

In a previous questionnaire study among 424 patients with chronic supraconal lesions, ${ }^{2}$ we found that the factor most strongly associated to colorectal dysfunction was complete SCI. Accordingly, in the chronic phase left colorectal and total gastrointestinal transit times were significantly longer in patients with complete than in patients with incomplete supraconal lesions. However, the numbers in each group were small and many patients with supraconal lesions were unable to participate in the study.

The method used for the assessment of gastrointestinal and segmental colonic transit times is based upon the assumption, that the 6 day period in which patients take markers is longer than the total gastrointestinal transit time. ${ }^{12}$ Therefore, the method is only valid if some markers have passed through the segment studied. In all patients but two at least two markers had passed through the rectosigmoid and consequently, we find the assumption of steady state valid.

As many patients with acute SCI have multiple lesions of other organs, making them unable to participate in such a study, selection bias will always be a problem. We studied 26 patients out of 73 admitted to the department. The patients unable to participate generally had more severe spinal cord lesions than those included in the study. Therefore, we probably underestimated the impact on colorectal function especially in patients with supraconal lesions.

In conclusion, SCI whether supraconal or located at the conus medullaris or cauda equina, causes severe colonic dysfunction. However, chronic conal or cauda equina lesions mainly result in prolonged rectosigmoid transit times. This indicates difficult evacuation of the rectum that may be due to direct injury to the reflex arc from the rectum to the sacral spinal cord. In contrast, supraconal lesions cause more generalized prolonged colonic transit times and less severe rectosigmoid dysfunction, probably due to an intact reflex arc between the rectum and sacral spinal cord.

\section{References}

1 Glickman S, Kamm MA. Bowel dysfunction in spinal-cordinjury patients. Lancet 1996; 347: 1651-1653.

2 Krogh $\mathrm{K}$ et al. Colorectal function in patients with spinal cord lesions. Dis Colon Rectum 1997; 40: 1233 - 1239.

3 Harari D et al. Constipation-related symptoms and bowel program concerning individuals with spinal cord injury. Spinal Cord 1997; 35: $394-401$.

4 Menter R et al. Bowel management outcomes in individuals with long-term spinal cord injuries. Spinal Cord 1997; 35: 608-612.

5 Johanson JF, Sonnenberg A, Koch TR, McCarty DJ. Association of constipation with neurologic diseases. Dig Dis Sci 1992; 37: $179-186$

6 Menardo G et al. Large-bowel transit in paraplegic patients. Dis Colon Rectum 1987; 30: $924-928$.

7 Beuret-Blanquart $\mathrm{F}$ et al. Colonic transit time and anorectal manometric anomalies in 19 patients with complete transection of the spinal cord. J Auton Nerv Syst 1990; 25: 109-112.

8 Devroede $\mathrm{G}$ et al. Traumatic constipation. Gastroenterology 1979; 77: $1258-1267$.

9 Biering-Sørensen F, Pederson V, Clausen S. Epidemiology of spinal cord lesions in Denmark. Paraplegia 1990; 28: 105-111.

10 Nino-Murcia M, Stone J, Chang P, Perkash I. Colonic transit in spinal cord-injured patients. Invest Radiol 1990; 25: 109-112.

11 Maynard Jr FM et al. International standards for neurological and functional classification of spinal cord injury. Spinal Cord 1997; 35: $266-274$.

12 Abrahamsson H, Antov S, Bosaeus I. Gastrointestinal and colonic segmental transit time evaluated by a single abdominal xray in healthy subjects and constipated patients. Scand $J$ Gastroenterol 1988; 23 (suppl 152): $72-80$.

13 Frisbie JH, Chopra S, Food D, Sakarati M. Colorectal cancer and myelopathy. J Am Paraplegic Soc 1984; 7: 33-36.

14 Gore RM, Mintzer RA, Calenoff L. Gastrointestinal complications of spinal cord injury. Spine 1981; 6: $538-544$.

15 Atkinson PP, Atkinson JLD. Spinal Shock. Mayo Clin Proc 1996; 71: $384-389$.

16 Denny-Brown DE, Robertson EG. An investigation of the nervous control of defecation. Brain 1935; 58: 256-310.

17 Kuhn WG. The care and rehabilitation of patients with injuries of the spinal cord and cauda equina. J Neurosurg 1947; 4: 40-68.

18 Keshavarzian A et al. Delayed colonic transit in spinal cordinjured patients measured by indium-111 amberlite scintigraphy. Am J Gastroenterol 1995; 90: 1295 - 1300.

19 Duthie HL. Surgery of the anus, rectum and colon. JC Goligher (ed). Balliere Tindall and Cassell: London, 1967, p 40. 